\title{
A NOTE ON LANGUAGE AND TRANSLITERATION
}

I have transliterated Greek language words according to the guidelines of the Journal of Modern Greek Studies. I have rendered the titles of Greek and English-language documents in the Archive of the Greek Orthodox Archdiocese in English for reasons of consistency. 

THE GREEK ORTHODOX CHURCH IN AMERICA 
